\title{
Inhibitory Effects of Sodium Arsenite and Acacia Honey on Acetylcholinesterase in Rats
}

\author{
Aliyu Muhammad, ${ }^{1,2}$ Oyeronke A. Odunola, ${ }^{1}$ Michael A. Gbadegesin, ${ }^{1}$ Abdullahi B. Sallau, \\ Uche S. Ndidi, ${ }^{2}$ and Mohammed A. Ibrahim ${ }^{2}$ \\ ${ }^{1}$ Department of Biochemistry, Cancer Research and Molecular Biology Laboratories, University of Ibadan, \\ Ibadan, Oyo State, Nigeria \\ ${ }^{2}$ Department of Biochemistry, Ahmadu Bello University, Zaria, Kaduna State, Nigeria
}

Correspondence should be addressed to Oyeronke A. Odunola; ronodunola@yahoo.com

Received 18 November 2014; Revised 21 January 2015; Accepted 27 January 2015

Academic Editor: Cheng-Xin Gong

Copyright (C) 2015 Aliyu Muhammad et al. This is an open access article distributed under the Creative Commons Attribution License, which permits unrestricted use, distribution, and reproduction in any medium, provided the original work is properly cited.

\begin{abstract}
This study was conducted to investigate the effect of sodium arsenite and Acacia honey on acetylcholinesterase (AChE) activity and electrolytes in the brain and serum of Wistar rats. Male Wistar albino rats in four groups of five rats each were treated with distilled water, sodium arsenite $(5 \mathrm{mg} / \mathrm{kg}$ body weight), Acacia honey $(20 \% \mathrm{v} / \mathrm{v})$, and sodium arsenite and Acacia honey, daily for one week. The sodium arsenite and Acacia honey significantly $(P<0.05)$ decreased AChE activity in the brain with the combined treatment being more potent. Furthermore, sodium arsenite and Acacia honey significantly $(P<0.05)$ decreased AChE activity in the serum. Strong correlation was observed between the sodium and calcium ion levels with acetylcholinesterase activity in the brain and serum. The gas chromatography mass spectrometry analysis of Acacia honey revealed the presence of a number of bioactive compounds such as phenolics, sugar derivatives, and fatty acids. These findings suggest that sodium arsenite and/or Acacia honey modulates acetylcholinesterase activities which may be explored in the management of Alzheimer's diseases but this might be counteracted by the hepatotoxicity induced by arsenics.
\end{abstract}

\section{Introduction}

Arsenic compounds are ubiquitous in nature and are released into the environment via industrial or agricultural processes as well as some medical applications [1]. Consumption of arsenicals such as sodium arsenite through contaminated water is prevalent in many areas of the world [2]. Sodium arsenite is a clastogen causing chromosomal breakage [3], which interacts with other substances like metals to potentiate its effects [4]. Its administration has been reported to compromise the integrity of the liver of mouse, rat, fish, and goat [5-7]. However, administration of sodium arsenite induces oxidative stress with severe demyelination and other morphological alterations in axons of peripheral nerves which may potentially induce changes in the generation and distribution of action potentials in peripheral nerves, thereby causing an impediment in transmission of nerve impulses [8]. It has been reported that arsenic can act as comutagen because of its ability to bind and inhibit the activities of thiol containing enzymes [9], such as DNA ligase [10] causing defects during DNA replication/repair, recombination, and joining of single- and double-stranded DNA breaks [11].

Alzheimer's disease is a progressive dementing neurodegenerative disorder in elderly, which is pathologically characterized by the presence of senile plaques and neurofibrillary changes in the brains of affected individuals [12]. High activities of acetylcholinesterase (EC 3.1.1.7) (AChE) in the brain have been implicated in the pathogenesis of the disease and its inhibition is considered as a viable therapeutic strategy in the management of the disease [13]. The main biochemical role of $\mathrm{AChE}$ is the termination of impulse transmission at cholinergic synapses by rapid hydrolysis of the neurotransmitter, acetylcholine (ACh) [13]. AChE exhibits a high specific activity similar to that of a diffusioncontrolled reaction [14]. 
Millions of people around the world get exposed to high levels of arsenic compounds in drinking-water which often largely affect rural dwellers. Considering the adverse effects of these arsenic compounds on the nervous system and the high prevalence of Alzheimer's disease among such rural dwellers, it is worthwhile to investigate the effects of the arsenic compounds on the pathophysiology of Alzheimer's disease. Unfortunately, however, such an important relationship has not been previously investigated either in humans or experimental animals.

On the other hand, most of the arsenics-exposed individuals as well as the Alzheimer's patients are frequently exposed to a number of functional foods. One of such functional foods is honey which has prophylactic and curative properties. Honey is basically a supersaturated solution of sugars, produced by honeybees via a regurgitation mechanism of plant parts [15-18] with fructose and glucose as the most abundant sugars present in it. Variety of constituents such as phenolic acids, flavonoids, enzymes, carotenoids, organic acids, and proteins have been reported to be present in honey [19-21]. In addition to the above-mentioned constituents, other bioactive compounds such as vitamins, antioxidants, and hydrogen peroxide are also reported to be present in honey [22]. Thus, honey as a natural source of antioxidant might reduce the risk of Alzheimer's disease because of the crucial role of oxidative stress in the pathogenesis of the disease [23]. It has also been documented that honey exhibits several medicinal properties which include antitumor, antimetastatic, and antiangiogenic effects [24]. Others are antibacterial, anti-inflammatory, immune-stimulant, antiulcer, and wound/burn healing properties [25]. Acacia honey is a type of honey produced by bees from the Acacia flowers, hence, the name. Earlier report from our laboratory demonstrated that daily administrations of Acacia honey to Wistar rats have some biological effects on the clinical and biochemical parameters [18]. We have also demonstrated its antiproliferative effects against prostate cancer cell line [16] and lung cancer cell line in vitro [17]. Furthermore, we have evidently demonstrated the fact that fractionation of Acacia honey negatively affected its antioxidant potentials by making it a radical generating agent in contrast to the unfractionated sample. In fact, the antioxidant potential of the whole Acacia honey was comparable to $\alpha$-tocopherol; a well-known standard antioxidant [15].

However, the effects of honey on Alzheimer's disease have not been fully investigated especially with respect to the possible modulation of heavy-metals (arsenics) associated toxicity during the disease. Hence, this study was conducted to investigate the possible effects of arsenic compounds (sodium arsenite) on the pathology of Alzheimer's disease as well as the modulatory role of Acacia honey on the heavymetals (arsenics) associated toxicity during the disease.

\section{Results}

In the in vitro study, Acacia honey and sodium arsenite demonstrated potent inhibition of AChE in a concentrationdependent pattern (Figures 1 and 2 ) with an exceptional $\mathrm{IC}_{50 \text { s }}$ of $0.26 \%(\mathrm{v} / \mathrm{v})$ and $0.0885 \mathrm{mM}$, respectively. Interestingly,

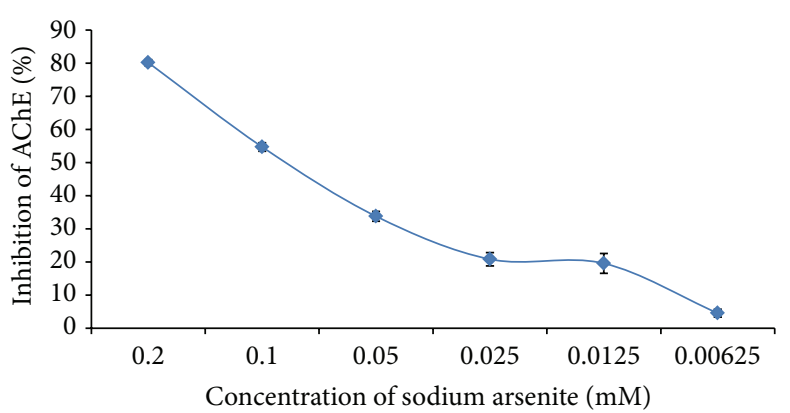

FIGURE 1: The effect of sodium arsenite on the activity of acetylcholinesterase in vitro. Values are presented as mean \pm SD.

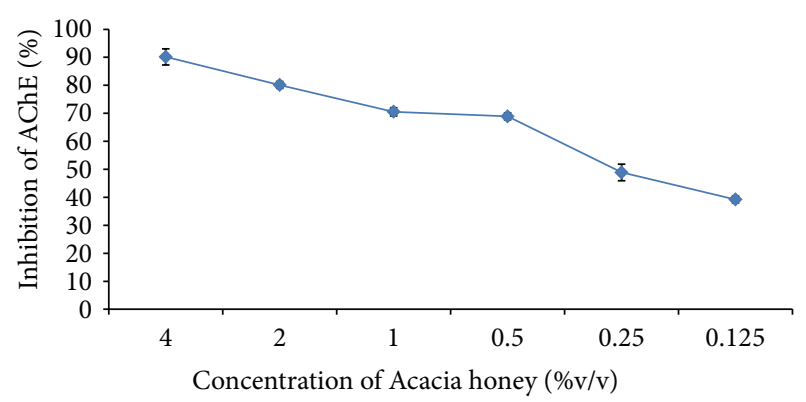

FIGURE 2: The effect of Acacia honey on the activity of acetylcholinesterase in vitro. Values are presented as mean \pm SD.

sodium arsenite also significantly $(P<0.05)$ inhibited AChE in the brain of the experimental animals but Acacia honey had a more significant inhibition of the brain AChE than sodium arsenite (Table 1). However, among all the treatments, the combined administration of Acacia honey and sodium arsenite demonstrated the most potent inhibition of the brain AChE (Table 1). There was no significant difference $(P<$ 0.05) in the serum levels of AChE among the treatment groups (Table 1).

A significant $(P<0.05)$ decrease in the brain $\mathrm{Ca}^{2+}$ and $\mathrm{Na}^{+}$levels was observed in the sodium arsenite and Acacia honey treated groups and the reduction in the brain levels of these electrolytes was more significant $(P<0.05)$ in the coadministered group (Table 2 ). There was no significant $(P>0.05)$ difference across all the groups in the brain $\mathrm{K}^{+}$ levels. All the treatments significantly $(P<0.05)$ decreased the brain levels of $\mathrm{Cl}^{-}$but there was no significant $(P>0.05)$ difference among the treated groups compared to the control (Table 2$)$. There was no significant $(P>0.05)$ difference across all the groups in the electrolyte levels in serum except when compared with control $(P<0.05)$ (Table 3$)$.

Bearing in mind the role of ions in the release of acetylcholine and vice versa, the correlation between AChE activity and electrolyte levels in brain and serum was calculated with a strong correlation between $\mathrm{Ca}^{2+}$ and $\mathrm{Na}^{+}$levels and AChE activity in the brain $\left(R^{2}=0.962\right.$ and 0.838$)$ with no correlation in terms of $\mathrm{K}^{+}$and $\mathrm{Cl}^{-}$levels. However, no strong correlations were observed between AChE activity and electrolyte level in serum. 
TABLE 1: The activity of AChE versus the percentage (\%) inhibition in the brain (cerebrum and cerebellum) and serum after Acacia honey and sodium arsenite administration in vivo.

\begin{tabular}{|c|c|c|c|c|c|}
\hline \multirow[t]{2}{*}{ Group } & \multirow[t]{2}{*}{ Treatment } & $\begin{array}{l}\text { AChE activity }(\mu \text { mole } / \mathrm{min} / \mathrm{g} \text { of } \\
\left.\text { tissue } / \mathrm{mg} \text { protein } \times 10^{-2}\right)\end{array}$ & $\begin{array}{l}\% \text { inhibition of } \mathrm{AChE} \\
\text { activity }\end{array}$ & $\begin{array}{c}\text { AChE activity }(\mu \mathrm{mole} / \mathrm{min} / \mathrm{mg} \\
\left.\text { protein } \times 10^{2}\right)\end{array}$ & $\begin{array}{l}\text { \% inhibition of } \\
\text { AChE activity }\end{array}$ \\
\hline & & \multicolumn{2}{|c|}{ Brain (cerebrum and cerebellum) } & \multicolumn{2}{|l|}{ Serum } \\
\hline 1 & Distilled water & $533.67 \pm 7.71^{\mathrm{b}, \mathrm{c}, \mathrm{d}}$ & 0.00 & $1.88 \pm 0.32^{\mathrm{a}, \mathrm{b}, \mathrm{c}}$ & 0.00 \\
\hline 2 & $20 \%$ honey & $302.45 \pm 5.65^{\mathrm{a}, \mathrm{c}, \mathrm{d}}$ & 43.33 & $1.74 \pm 0.43^{\mathrm{a}}$ & 7.45 \\
\hline 3 & $\begin{array}{l}5 \mathrm{mg} / \mathrm{kg} \text { sodium } \\
\text { arsenite }\end{array}$ & $471.55 \pm 11.58^{\mathrm{a}, \mathrm{b}, \mathrm{d}}$ & 11.64 & $1.72 \pm 0.19^{\mathrm{a}}$ & 8.51 \\
\hline 4 & $\begin{array}{c}20 \% \text { honey }+ \\
5 \mathrm{mg} / \mathrm{kg} \text { sodium } \\
\text { arsenite }\end{array}$ & $243.76 \pm 4.23^{\mathrm{a}, \mathrm{b}, \mathrm{c}}$ & 54.33 & $1.73 \pm 0.54^{\mathrm{a}}$ & 7.98 \\
\hline
\end{tabular}

Values are presented as mean $\pm \mathrm{SD}$; a: statistical significant $(P<0.05)$ as compared with Group 1, b: statistical significance $(P<0.05)$ as compared with Group 2 , c: statistical significance $(P<0.05)$ as compared with Group 3, and d: statistical significance $(P<0.05)$ as compared with Group 4 .

TABLE 2: The electrolyte levels in brain (cerebrum and cerebellum) after Acacia honey and sodium arsenite administration in vivo.

\begin{tabular}{lcrrrr}
\hline Group & Treatment & $\mathrm{Ca}^{2+}\left(\mathrm{mg} / \mathrm{dL} \times 10^{-2}\right)$ & $\mathrm{Na}^{+}(\mathrm{mM})$ & $\mathrm{K}^{+}\left(\mathrm{mM}^{2}\right)$ & $\mathrm{Cl}^{-}(\mathrm{mM})$ \\
\hline 1 & Distilled water & $9.20 \pm 0.50^{\mathrm{b}, \mathrm{c}, \mathrm{d}}$ & $132.00 \pm 2.00^{\mathrm{b}, \mathrm{c}, \mathrm{d}}$ & $31.08 \pm 4.95$ & $134.60 \pm 3.78^{\mathrm{b}, \mathrm{c}, \mathrm{d}}$ \\
2 & 20\% honey & $4.00 \pm 0.30^{\mathrm{a}, \mathrm{c}, \mathrm{d}}$ & $120.00 \pm 7.98^{\mathrm{a}, \mathrm{c}, \mathrm{d}}$ & $32.77 \pm 5.36$ & $122.40 \pm 8.11^{\mathrm{a}}$ \\
3 & $5 \mathrm{mg} / \mathrm{kg}$ sodium arsenite & $6.66 \pm 1.10^{\mathrm{a}, \mathrm{b}, \mathrm{d}}$ & $127.60 \pm 8.01^{\mathrm{a}, \mathrm{b}, \mathrm{d}}$ & $29.38 \pm 3.74$ & $124.40 \pm 8.11^{\mathrm{a}}$ \\
4 & $20 \%$ honey $+5 \mathrm{mg} / \mathrm{kg}$ sodium arsenite & $3.00 \pm 0.20^{\mathrm{a}, \mathrm{b}, \mathrm{c}}$ & $102.00 \pm 8.00^{\mathrm{a}, \mathrm{b}, \mathrm{c}}$ & $29.39 \pm 4.94$ & $123.00 \pm 9.58^{\mathrm{a}}$ \\
\hline
\end{tabular}

Values are presented as mean $\pm \mathrm{SD}$; a: statistical significance $(P<0.05)$ as compared with Group 1, b: statistical significance $(P<0.05)$ as compared with Group 2, c: statistical significance $(P<0.05)$ as compared with Group 3, and d: statistical significance $(P<0.05)$ as compared with Group 4.

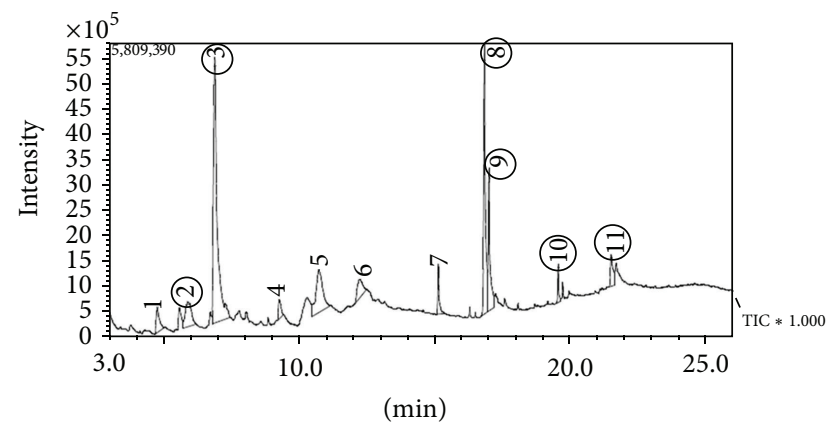

FIGURE 3: GC-MS analysis results of Acacia honey.

The GC-MS chromatogram of the Acacia honey is presented in Figure 3 and the list of proposed bioactive components was presented in Table 4. Figure 4 shows the vitamin contents of Acacia honey with vitamin A being highest in content followed by vitamin C. Some important mineral elements (Figure 4) of physiological importance like calcium, iron, magnesium, potassium and zinc. The concentration of these elements in Acacia honey is in the order: iron $>$ magnesium $>$ potassium $>$ calcium $>$ zinc.

\section{Discussion}

Acetylcholine (ACh) is a neurotransmitter that functions in conveying nerve impulses across synaptic clefts within the central nervous system (CNS) [26]. Following the transmission of an impulse across the synapse by the release of $\mathrm{ACh}$, $\mathrm{AChE}$ is released into the synaptic cleft [27]. This enzyme

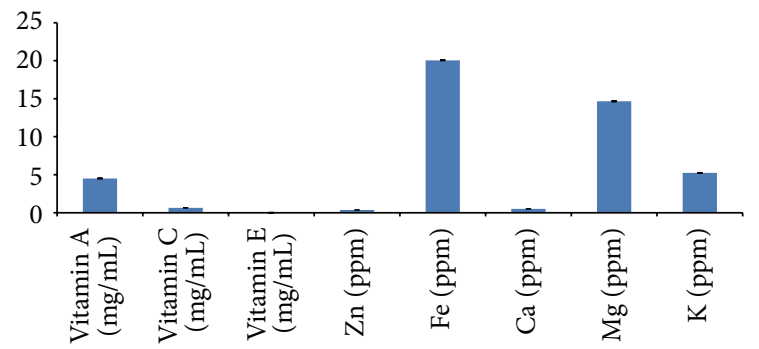

FIgURE 4: The vitamin and mineral contents of Acacia honey. The mineral element contents of Acacia honey. Values are presented as mean $\pm \mathrm{SD}$.

hydrolyzes ACh to choline and acetate, and transmission of the nerve impulse is terminated [28]. In this study, we report the effects of sodium arsenite and Acacia honey on acetylcholinesterase activity as well as the relationship with electrolyte levels.

Arsenic compounds are known to exert toxicity by binding and inactivating thiol groups in proteins [9] and this phenomenon could account for the observed in vitro inhibition of the AChE by the sodium arsenite. Interestingly, the sodium arsenite was also able to inhibit the AChE in the brain which might suggest that this compound possesses the ability to cross the blood-brain barrier and modulate the function of the enzyme via binding to the thiol groups of the protein. Also, the observed inhibitory effects of sodium arsenite on the brain AChE were potentiated by Acacia honey, which could be linked to the active ingredients in honey that are perhaps lipophilic in nature and, therefore, could increase 
TABLE 3: The electrolyte levels in serum after Acacia honey and sodium arsenite administration in vivo.

\begin{tabular}{|c|c|c|c|c|c|}
\hline Group & Treatment & $\mathrm{Ca}^{2+}(\mathrm{mg} / \mathrm{dL})$ & $\mathrm{Na}^{+}(\mathrm{mM})$ & $\mathrm{K}^{+}(\mathrm{mM})$ & $\mathrm{Cl}^{-}(\mathrm{mM})$ \\
\hline 1 & Distilled water & $10.86 \pm 0.43$ & $144.00 \pm 1.52$ & $5.92 \pm 1.93$ & $100.33 \pm 0.57$ \\
\hline 2 & $20 \%$ honey & $11.95 \pm 0.84$ & $143.00 \pm 1.41$ & $5.20 \pm 1.70$ & $101.25 \pm 0.95$ \\
\hline 3 & $5 \mathrm{mg} / \mathrm{kg}$ sodium arsenite & $10.77 \pm 0.75$ & $142.66 \pm 2.51$ & $6.06 \pm 1.40$ & $102.00 \pm 0.00$ \\
\hline 4 & $20 \%$ honey $+5 \mathrm{mg} / \mathrm{kg}$ sodium arsenite & $11.61 \pm 0.60$ & $140.00 \pm 0.00$ & $5.45 \pm 0.91$ & $101.20 \pm 1.09$ \\
\hline
\end{tabular}

Values are presented as mean $\pm \mathrm{SD}$; a: statistical significance $(P<0.05)$ as compared with Group 1, b: statistical significance $(P<0.05)$ as compared with Group 2, c: statistical significance $(P<0.05)$ as compared with Group 3, d: statistical significance $(P<0.05)$ as compared with Group 4.

TABLE 4: The result of GC-MS analysis of Acacia honey.

\begin{tabular}{|c|c|c|c|c|}
\hline $\mathrm{S} / \mathrm{N}$ & Proposed compounds & Lane (peak) & Similarity index (\%) & Proportion (\%) \\
\hline 1 & 2,4-Dihydroxy-5-methylpyrimidine & 1 & 77 & 3.09 \\
\hline 2 & Pyrazol-3-one & 2 & 76 & 6.07 \\
\hline 3 & 5-Hydroxymethylfurfural & 3 & 92 & 37.96 \\
\hline 4 & D-Allose & 4 & 94 & 11.56 \\
\hline 5 & 1,6-Anhydro-beta-D-glucofuranose & 5 & 92 & 3.88 \\
\hline 6 & n-Hexadecanoic acid & 6 & 92 & 2.72 \\
\hline 7 & Hydrofol acid & 7 & 94 & 9.44 \\
\hline 8 & 9-Octadecanoic acid-2-hydroxy-1-(hydroxymethyl) ethyl ester & 8 & 81 & 3.21 \\
\hline 9 & p-Hydroxybenzoic acids & 9 & 84 & 1.58 \\
\hline 10 & Cinnamic acid & 10 & 82 & 1.08 \\
\hline 11 & Chrysin & 11 & 82 & 1.99 \\
\hline
\end{tabular}

the effective concentration of the sodium arsenite entering the brain. It is also possible that the potentiation of sodium arsenite inhibitory activity was due to the identified phenolic compounds such as p-hydroxybenzoic acid, cinnamic acid, and chrysin present in the Acacia honey which could also inhibit the AChE. Indeed, phenolics such as anacardic acids, cardols, cardanols, and methylcardols have been reported to inhibit AChE [29]. Overall, the foregoing observations suggest that sodium arsenite and/or Acacia honey could be beneficial in the management of Alzheimer's disease in this regard. Inhibition of AChE implies more of ACh in circulation, which has been reported to bind to angiotensin II, thereby preventing angiotensin II induced oxidative stress [30].

Serum cholinesterases presumably originate in liver cells but other organs also contribute to the pool of these enzymes in the plasma [31]. Activity of serum AChE could be an index of liver function and low activity of the enzyme has been reported in so many liver dysfunctions like jaundice and cirrhosis $[3,32]$. Our findings indicated that the sodium arsenite and/or Acacia honey could lower the serum levels of AChE, though insignificantly, which seemingly indicate hepatotoxicity. Some identified components of Acacia honey such as pyrazol-3-one and 9-octadecanoic acid-2-hydroxy-1(hydroxymethyl) ethyl ester as well as the sodium arsenite have been reported to be hepatotoxic $[33,34]$. However, it is plausible to suggest that sodium arsenite and/or Acacia honey have some beneficial effects on hepatic cells but the inhibitory effects of the sodium arsenite as well as the identified components of the honey on thiol containing proteins led to a decline in the activity of the serum enzyme. Overall, information derived from the serum tends to suggest that these agents have some level of hepatotoxicity.

Balance in the levels of $\mathrm{Ca}^{2+}$ and $\mathrm{Na}^{+}$in the brain and blood is a prerequisite for neurotransmission. Our results showed that the activity of AChE positively correlates with the levels of these ions. The role of $\mathrm{Ca}^{2+}$ and $\mathrm{Na}^{+}$in neurotransmission in regulating the release of neurotransmitters and in the pathogenesis of neurological diseases has been investigated [35]. When presynaptic cell releases a brief pulse of ACh, both sites on the postsynaptic cell receptor are occupied briefly and the channel opens, which allow the passage of either $\mathrm{Ca}^{2+}$ or $\mathrm{Na}^{+}$. The inward flux of these ions depolarizes the plasma membrane, initiating subsequent events that vary with the type of tissue [36]. High concentration of $\mathrm{Ca}^{2+}$ and low concentration of $\mathrm{Na}^{+}$are required for $\mathrm{AChE}$ release but the consistent decrease in AChE activity in this study means that there is more $\mathrm{ACh}$ than $\mathrm{AChE}$ present to facilitate the synaptic nerve transfer. Interestingly, sodium channels play a central role in action potential generation and are uniquely poised to influence the efficacy of transmitter release [37].

Oxidative processes have been implicated in the onset and development of degenerative diseases and foods rich in polyphenols [38], vitamins, and minerals [39] may have a nutritional and health beneficial effects based on our findings.

\section{Conclusion}

Data from this study suggest that exposure to sodium arsenite could be beneficial in the management of Alzheimer's disease; however, it seems toxic to hepatic tissues. Furthermore, Acacia honey could potentiate the action of sodium arsenite in 
both cases and therefore may be explored in the management of Alzheimer's disease.

\section{Materials and Methods}

5.1. Chemicals and Reagents. Sodium arsenite $(5 \mathrm{mg} / \mathrm{kg}$ body weight) equivalent to two-tenth of the oral $\mathrm{LD}_{50}[40]$ was used in all experiments. Acacia honey was dissolved in distilled water to prepare a $20 \%(\mathrm{v} / \mathrm{v})$ honey solution and $5 \mathrm{~mL} / \mathrm{kg}$ body weight (b.w.) was used [18]. All other reagents and chemicals used were of analytical grade.

5.2. Sample Collection. Honey produced by Apis mellifera was collected from the North-West frontier of Pakistan during spring season of 2012 from Acacia modesta flower, identified, and maintained at $4^{\circ} \mathrm{C}$ until analysis, at the Industrial Analytical Centre, International Center for Chemical and Biological Sciences, University of Karachi, Karachi, Pakistan.

5.3. Determination of In Vitro Acetylcholinesterase Inhibitory Activity of Sodium Arsenite and Acacia Honey. The activity of AChE (Sigma-Aldrich) was determined spectrophotometrically by the modified method of Ellman's et al. [41] using acetylthiocholine iodide as substrate and 5-5 ${ }^{\prime}$ - dithiobis (2-nitrobenzoic) acid [DTNB] as a chromogen. Varying concentrations of sodium arsenite $(0.2,0.1,0.05,0.025,0.0125$, and $0.00625 \mathrm{mM})$ and honey $(0.125,0.25,0.5,1.0,2.0$, and $4.0 \% \mathrm{v} / \mathrm{v})$ were used for inhibition studies, respectively. The reaction of DTNB with thiocholine released by the enzymatic hydrolysis of acetylthiocholine iodide was monitored at a wavelength of $412 \mathrm{~nm}$. The percentage inhibition was calculated against the untreated enzymes and the $\mathrm{IC}_{50}$ determined.

5.4. Experimental Animals and Design. Twenty-four (24) male Wistar rats (150-195 g) were used in the present study. They were allowed to adapt for one week under standard laboratory conditions of $12 \mathrm{hr}$ light-dark cycle before commencement of all experiments. The rats were maintained in the animal house of International Centre of Chemical and Biological Sciences, University of Karachi, Pakistan, with protocol for the study approved by the Institutional Animal Right Review Committee. During acclimatization, the rats were allowed free access to NIH-07 pelletized diet and water. In addition, all rats were catered in accordance with the National Institute of Health (NIH) Guide for the care and Use of Laboratory Animals. They were randomly grouped into four (4) groups of six (6) rats each. The animals were treated daily for seven days as shown in the experimental design below:

\section{Group 1: distilled water only;}

Group 2: $5 \mathrm{mg} / \mathrm{kg}$ b.w. sodium arsenite equivalent to $20 \%$ of oral $\mathrm{LD}_{50}[40]$;

Group 3: $20 \%$ v/v Acacia honey $+5 \mathrm{mg} / \mathrm{kg}$ b.w. sodium arsenite;

Group 4: $20 \%$ v/v Acacia honey at $5 \mathrm{~mL} / \mathrm{kg}$ b.w.
5.5. Collection of Tissues and Blood Samples. Twenty-four (24) hrs after the last treatment, the rats were humanely sacrificed with sodium pentothal $(60 \mathrm{mg} / \mathrm{kg}$ b.w.) after an overnight fast. The clotted blood samples were centrifuged at $3500 \times \mathrm{g}$ at $-4^{\circ} \mathrm{C}$ for 10 minutes to obtain the serum which was kept at $-80^{\circ} \mathrm{C}$ until further analysis. The brain (cerebrum and cerebellum) and blood serum were also collected and the brain was homogenized in 1:5 of phosphate buffer ( $\mathrm{pH} 7.4$ ), centrifuged at $3500 \times \mathrm{g}$ at $4^{\circ} \mathrm{C}$ for 10 minutes, and kept at $-80^{\circ} \mathrm{C}$ until further analysis. Each time the supernatant/serum was outside the freezer, it was kept in ice bags. Using Auto Analyzer Hitachi Roche 7020 (902, Japan Inc.) the total protein contents of the serum and tissues were determined using the standard manufacturer's protocol.

5.6. Determination of Acetylcholinesterase Activity In Vivo. The activities of AChE in the blood serum and brain were determined spectrophotometrically by the method of Ellman's et al. [41] as modified by Srikumar et al. [42] using acetylthiocholine iodide as appropriate substrate and $5-5^{\prime}$ dithiobis (2-nitrobenzoic) acid [DTNB] as a chromogen. The reaction of DTNB with thiocholine released by the enzymatic hydrolysis of acetylthiocholine iodide was monitored at $412 \mathrm{~nm}$. The specific activity of AChE was expressed as $\mu \mathrm{mole} / \mathrm{gram}$ of tissue/minute/mg protein for brain and $\mu \mathrm{mole} / \mathrm{minute} / \mathrm{mg}$ protein for serum.

5.7. Determination of Electrolytes. Electrolytes levels were quantified in serum and brain tissues by using Auto Analyzer Hitachi Roche 7020 (902) according to manufacturer's protocols for calcium ion, whereas the levels of potassium, sodium, and chloride ions were determined by electrolyte analyzer (Ion Selective Electrode, China) according to manufacturer's protocol.

5.8. Qualitative Identification of the Proposed Active Principles of Acacia Honey. Gas chromatography/mass spectrometry (GC-MS) was carried out by Shimadzu GCMS-QP2010 PLUS Japan according to manufacturer's protocol.

5.9. Determination of Mineral Elements in Acacia Honey. The mineral elements: calcium, iron, potassium, magnesium, and zinc, were determined using Atomic Absorption Spectrometry (AAS) machine according to manufacturer's protocol.

5.10. Determination of Vitamins in Acacia Honey. Vitamins $\mathrm{A}, \mathrm{C}$, and $\mathrm{E}$ were determined in the honey after adopting the methods of Rutkowski and Grzegorczyk [43] and Dahot et al. [44].

5.11. Statistical Analysis. To address the biological variability and stability of the samples, each and every experiment was repeated at least three times and the results were expressed as mean \pm standard deviation. Differences between the groups were analyzed by one-way analysis of variance (ANOVA) with the aid of Statistical Package for Social Sciences (SPSS) software, SPSS Inc., Chicago, Standard version 20.0. $P$ values $<0.05$ were considered significant for differences in mean using the least of significance difference (LSD). 


\section{List of Abbreviations}

(AChE): Acetylcholinesterase

(ACh): Acetylcholine

(DTNB): 5-5'-Dithiobis 2-nitrobenzoic acid

(AAS): Atomic absorption spectrometry

(GC-MS): Gas chromatography mass spectrophotometry

(CNS): Central nervous system

(ANOVA): Analysis of variance

(LSD): Least of significance difference

(SPSS): Statistical package for social sciences.

\section{Conflict of Interests}

The authors declare that there is no conflict of interests with regard to the publication of this paper.

\section{Acknowledgment}

The authors appreciate funding and the provision of facilities granted by the Management of International Center for Chemical and Biological Sciences, University of Karachi, Karachi 75270, Pakistan, towards the successful completion of this work (Muhammad Aliyu, P20, 348).

\section{References}

[1] P. C. Chan and J. Huff, "Arsenic carcinogenesis in animals and in humans: mechanistic, experimental, and epidemiological evidence," Journal of Environmental Science and Health-Part C Environmental Carcinogenesis and Ecotoxicology Reviews, vol. 15, no. 2, pp. 83-122, 1997.

[2] A. Chatterjee, D. Das, and D. Chakraborti, "A study of ground water contamination by arsenic in the residential area of behala, calcutta due to industrial pollution," Environmental Pollution, vol. 80, no. 1, pp. 57-65, 1993.

[3] S. E. Owumi, O. A. Odunola, and M. Aliyu, "Co-administration of sodium arsenite and ethanol: protection by aqueous extract of Aframomum longiscapum seeds," Pharmacognosy Research, vol. 4, no. 3, pp. 154-160, 2012.

[4] O. A. Odunola, K. A. Akinwumi, B. Ogunbiyi, and O. Tugbobo, "Interaction and enhancement of the toxic effects of sodium arsenite and lead acetate in wistar rats," African Journal of Biomedical Research, vol. 10, no. 1, pp. 59-65, 2007.

[5] A. Sharma, M. K. Sharma, and M. Kumar, "Modulatory role of Emblica officinalis fruit extract against arsenic induced oxidative stress in Swiss albino mice," Chemico-Biological Interactions, vol. 180, no. 1, pp. 20-30, 2009.

[6] S. Roy, M. Roy, P. K. Pandey, and S. P. Tiwari, "Effects of tissue trace minerals status and histopathological changes in chronic arsenicosis in goats," Veterinary World, vol. 2, no. 1, pp. 8-9, 2009.

[7] S. S. Vutukuru, N. Arun Prabhath, M. Raghavender, and A. Yerramilli, "Effect of arsenic and chromium on the serum amino-transferases activity in Indian major carp, Labeo rohita," International Journal of Environmental Research and Public Health, vol. 4, no. 3, pp. 224-227, 2007.

[8] E. García-Chávez, B. Segura, H. Merchant, I. Jiménez, and L. M. del Razo, "Functional and morphological effects of repeated sodium arsenite exposure on rat peripheral sensory nerves,"
Journal of the Neurological Sciences, vol. 258, no. 1-2, pp. 104110, 2007.

[9] F. W. Sunderman Jr., "Recent advances in metal carcinogenesis," Annals of Clinical and Laboratory Science, vol. 14, no. 2, pp. 93122,1984

[10] J.-H. Li and T. G. Rossman, "Inhibition of DNA ligase activity by arsenite: a possible mechanism of its comutagenesis," Molecular Toxicology, vol. 2, no. 1, pp. 1-9, 1989.

[11] D. D. Lasko, A. E. Tomkinson, and T. Lindahl, "Eukaryotic DNA ligases," Mutation Research, vol. 236, no. 2-3, pp. 277-287, 1990.

[12] T. Tomita, "At the frontline of Alzheimer's disease treatment: $\gamma$-secretase inhibitor/modulator mechanism," NaunynSchmiedeberg's Archives of Pharmacology, vol. 377, no. 4-6, pp. 295-300, 2008.

[13] E. A. Barnard, "Neuromuscular transmission-enzymatic destruction of acetylcholine," in The Peripheral Nervous System, J. I. Hubbard, Ed., pp. 201-224, Plenum Press, New York, NY, USA, 1974.

[14] D. M. Quinn, "Acetylcholinesterase: enzyme structure, reaction dynamics, and virtual transition states," Chemical Reviews, vol. 87, no. 5, pp. 955-979, 1987.

[15] M. Aliyu, O. A. Odunola, A. D. Farooq et al., "Fractionation of Acacia honey affects its antioxidant potential in vitro," Journal of Acute Disease, pp. 115-119, 2012.

[16] M. Aliyu, O. A. Odunola, A. D. Farooq et al., "Acacia honey modulates cell cycle progression, pro-inflammatory cytokines and calcium ions secretion in PC-3 cell lines," Journal of Cancer Science and Therapy, vol. 4, no. 12, pp. 401-407, 2012.

[17] M. Aliyu, O. A. Odunola, A. D. Farooq et al., "Molecular mechanism of antiproliferation potential of Acacia honey on NCI-H460 cell line," Nutrition and Cancer, vol. 65, no. 2, pp. 296-304, 2013.

[18] A. Muhammad, O. A. Odunola, S. E. Owumi et al., "Daily consumption of honey: effects on male wistar albino rats," International Journal of Food Nutrition and Safety, vol. 1, no. 2, pp. 66-74, 2012.

[19] E. Anklam, "A review of the analytical methods to determine the geographical and botanical origin of honey," Food Chemistry, vol. 63, no. 4, pp. 549-562, 1998.

[20] N. Gheldof, X.-H. Wang, and N. J. Engeseth, "Identification and quantification of antioxidant components of honeys from various floral sources," Journal of Agricultural and Food Chemistry, vol. 50, no. 21, pp. 5870-5877, 2002.

[21] J. Tchoumboue, J. Awah-Ndukum, F. A. Fonteh, N. D. Dongock, J. Pinta, and Z. A. Mvondo, "Physico-chemical and microbiological characteristics of honey from the Sudano-Guinean zone of West Cameroon," African Journal of Biotechnology, vol. 6, no. 7, pp. 908-913, 2007.

[22] S. Mohammadzadeh, M. Sharriatpanahi, M. Hamedi, Y. Amanzadeh, S. S. E. Ebrahimi, and S. N. Ostad, "Antioxidant power of Iranian propolis extract," Food Chemistry, vol. 103, no. 3, pp. 729-733, 2007.

[23] M. Mijanur Rahman, S. H. Gan, and M. I. Khalil, "Neurological effects of honey: current and future prospects," Evidence-Based Complementary and Alternative Medicine, vol. 2014, Article ID 958721, 13 pages, 2014.

[24] M. R. Hanaa and M. M. Y. Shaymaa, "Enhancement of the antitumor effect of honey and some of its extracts using adiponectin hormone," Australian Journal of Basic and Applied Sciences, vol. 5, no. 6, pp. 100-108, 2011. 
[25] M. Fiorani, A. Accorsi, M. Blasa, G. Diamantini, and E. Piatti, "Flavonoids from Italian multifloral honeys reduce the extracellular ferricyanide in human red blood cells," Journal of Agricultural and Food Chemistry, vol. 54, no. 21, pp. 8328-8334, 2006.

[26] A. Tripathi and U. C. Srivastava, "Acetylcholineasterase: a versatile enzyme of the nervous system," Annals of Neurosciences, vol. 15, pp. 106-110, 2008.

[27] H. T. Horton, L. A. Moran, K. G. Scrimgeour, M. D. Perry, and D. J. Rawn, Principles of Biochemistry, Pearson Higher Education International, 4th edition, 2006.

[28] A. Liesener, A.-M. Perchuc, R. Schöni, N. H. Schebb, M. Wilmer, and U. Karst, "Screening of acetylcholinesterase inhibitors in snake venom by electrospray mass spectrometry," Pure and Applied Chemistry, vol. 79, no. 12, pp. 2339-2349, 2007.

[29] M. Stasiuk, A. Janiszewska, and A. Kozubek, "Phenolic lipids affect the activity and conformation of acetylcholinesterase from Electrophorus electricus (Electric eel)," Nutrients, vol. 6, no. 5, pp. 1823-1831, 2014.

[30] J.-J. Liu, D.-L. Li, J. Zhou et al., "Acetylcholine prevents angiotensin II-induced oxidative stress and apoptosis in H9c2 cells," Apoptosis, vol. 16, no. 1, pp. 94-103, 2011.

[31] M. S. García-Ayllón, M. X. Silveyra, A. Candela et al., "Changes in liver and plasma acetylcholinesterase in rats with cirrhosis induced by bile duct ligation," Hepatology, vol. 43, no. 3, pp. 444-453, 2006.

[32] W. Burnett, "An assessment of the value of serum cholinesterase as a liver function test and in the diagnosis of jaundice," Gut, vol. 1, pp. 294-302, 1960.

[33] G. de Bodt, "Les miels de rhododendrons," Les Carnets du CARI, no. 50, pp. 10-12, 1996.

[34] P. Castaldo, M. Cataldi, S. Magi, V. Lariccia, S. Arcangeli, and S. Amoroso, "Role of the mitochondrial sodium/calcium exchanger in neuronal physiology and in the pathogenesis of neurological diseases," Progress in Neurobiology, vol. 87, no. 1, pp. 58-79, 2009.

[35] L. N. David and M. C. Michael, Lehninger Principles of Biochemistry, W. H. Freeman, New York, NY, USA, 4th edition, 2005.

[36] M. Prakriya and S. Mennerick, "Selective depression of lowrelease probability excitatory synapses by sodium channel blockers," Cell Press, vol. 26, no. 3, pp. 671-682, 2000.

[37] J. J. Clare, S. N. Tate, M. Nobbs, and M. A. Romanos, "Voltagegated sodium channels as therapeutic targets," Drug Discovery Today, vol. 5, no. 11, pp. 506-520, 2000.

[38] G. Chiva-Blanch and F. Visioli, "Polyphenols and health: moving beyond antioxidants," Journal of Berry Research, vol. 2, no. 2, pp. 63-71, 2012.

[39] A. Muhammad, O. A. Odunola, M. A. Gbadegesin, A. M. Adegoke, J. O. Olugbami, and N. S. Uche, "Modulatory role of Acacia honey from north-west Nigeria on sodium arseniteinduced clastogenicity and oxidative stress in male Wistar rats," Natural Product Research, vol. 29, no. 4, pp. 321-326, 2014.

[40] R. J. Preston, B. J. Dean, S. Galloway, H. Holden, A. F. McFee, and M. Shelby, "Mammalian in vivo cytogenetic assays. Analysis of chromosome aberrations in bone marrow cells," Mutation Research, vol. 189, no. 2, pp. 157-165, 1987.

[41] G. L. Ellman, K. D. Courtney, V. Andres Jr., and R. M. Featherstone, "A new and rapid colorimetric determination of acetylcholinesterase activity," Biochemical Pharmacology, vol. 7, no. 2, pp. 88-95, 1961.
[42] B. N. Srikumar, K. Ramkumar, T. R. Raju, and B. S. Shankaranarayana Rao, "Assay of acetylcholinesterase activity in the brain," in Brain and Behavior, pp. 142-144, National Institute of Mental Health and Neuro Sciences, Bangalore, India, 2004.

[43] M. Rutkowski and K. Grzegorczyk, "Modifications of spectrophotometric methods for antioxidative vitamins determination convenient in analytic practice," Acta Scientiarum Polonorum, Technologia Alimentaria, vol. 6, no. 3, pp. 17-28, 2007.

[44] M. U. Dahot, M. A. Memon, and M. A. Memon, "UVspectrophotometric determination of $\alpha$-tocopherol acetate in pharmaceutical preparations," Pakistan Journal of Pharmaceutical Sciences, vol. 3, no. 1, pp. 53-59, 1990. 


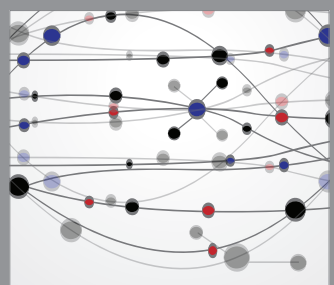

The Scientific World Journal
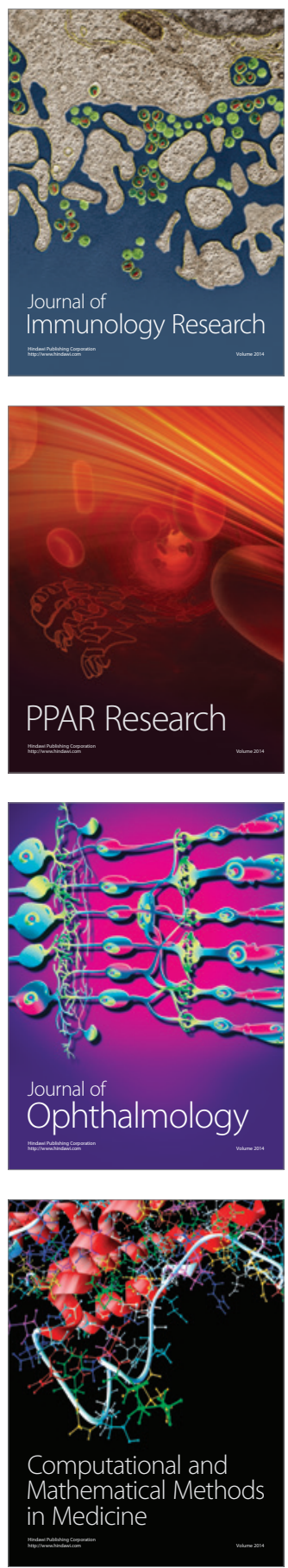

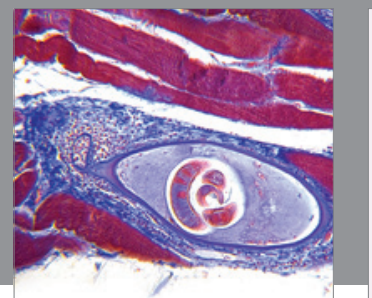

Gastroenterology

Research and Practice
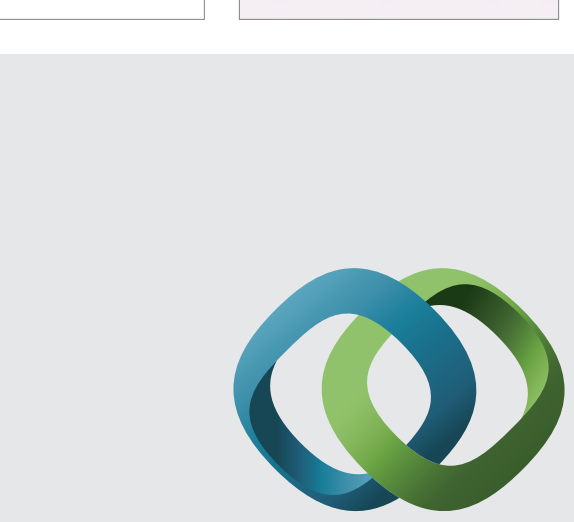

\section{Hindawi}

Submit your manuscripts at

http://www.hindawi.com
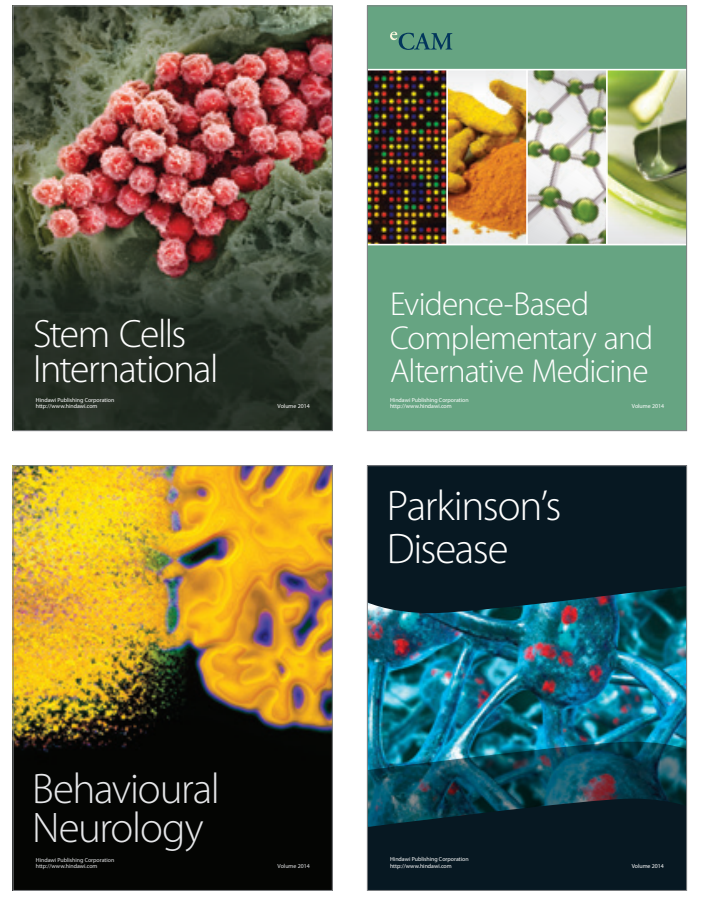
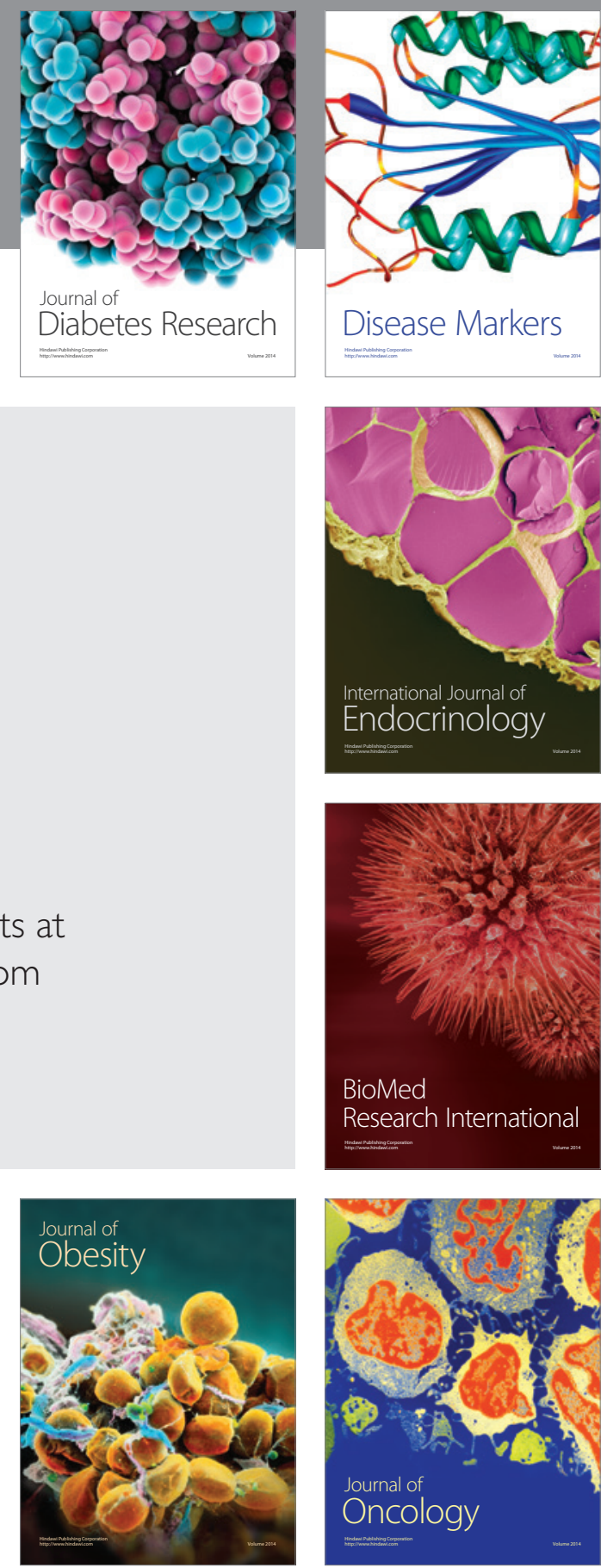

Disease Markers
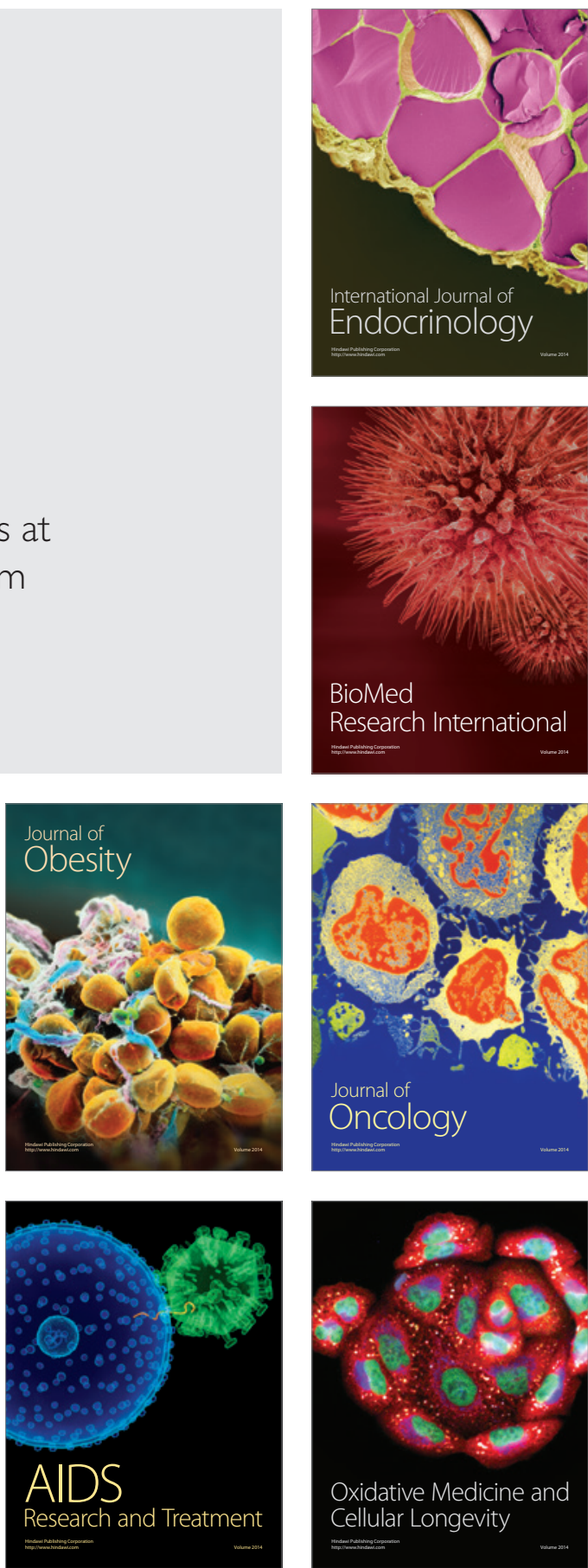